\title{
Penelitian Stabilitas Struktur Tanah Lempung Bersifat Monmorillonite Menggunakan Limbah Ampas Kopi
}

\section{Research on the Stability of Monmorillonite Clay Soil Structures Using Coffee Waste}

\author{
Hadi Santoso ${ }^{1}$, Yosef Cahyo ${ }^{2}$, Ahmad Ridwan ${ }^{3}$, Dwifi Aprillia Karisma ${ }^{4}$ \\ ${ }^{1}$ Jurusan Teknik Sipil, Fakultas Teknik, Universitas Kadiri, Jl. Selomangleng 1 Kediri Indonesia. Email : \\ hadipeyek@gmail.com \\ ${ }^{2}$ Jurusan Teknik Sipil, Fakultas Teknik, Universitas Kadiri, Jl. Selomangleng 1 Kediri Indonesia. Email : \\ yosef.cs@unik-kediri.ac.id \\ ${ }^{3}$ Jurusan Teknik Sipil, Fakultas Teknik, Universitas Kadiri, Jl. Selomangleng 1 Kediri Indonesia. Email : \\ ahmad_ridwan@unik-kediri.ac.id \\ ${ }^{4}$ Jurusan Teknik Sipil, Fakultas Teknik, Universitas Kadiri, Jl. Selomangleng 1 Kediri Indonesia. Email : \\ dwifiaprilliakarisma@gmail.com
}

\begin{abstract}
Abstrak
Dalam bidang konstruksi Tanah adalah suatu media pijakan inti dari sebuah bangunan. Struktur Tanah yang sebagian banyak terdapat lempung didalam komponennya adalah bersifat Monmorillonite. Tingkat stabilitas tanah yang bersifat Montmorillonite terbilang kurang bagus terhadap daya topang infrastruktur bangunan. Cara stabilitas tanah pada penelitian berikut adalah dengan menggunakan limbah ampas kopi pada variasi penambahan 5\%, 10\%, 15\% dan 20\% pada tanah Montmorillonite. Pada test uji stabilitas tanah adalah dengan menggunakan benda uji mix tanah montmorillonite dengan limbah ampas kopi dengan melakukan uji Berat Isi, Batas konsistensi (Atterberg Limit) dan Pemadatan Tanah (Proctor). Pada hasil penelitian struktur tanah asli dikategorikan momoroillonite dan setelah ditambah ampas kopi pada penambahan divariasi maksimal sebesar 20\%, nilai Liquid Limit naik menjadi 43\% dan nilai Plastic Limit mengalami kenaikan menjadi 31,64\%, sehingga index plastic dapat mengalami peningkatan menjadi 11,36\%. Saat uji pemadatan dengan kondisi benda uji padat sempurna, berat volume kering tanah asli sebesar 6,72 $\mathrm{gr} / \mathrm{cm} 3$ dan setelah ditambahkan limbah ampas kopi sebesar $20 \%$ mengalami peningkatan berat volume kering menjadi 10,56 gr/cm3.
\end{abstract}

Kata Kunci: Tanah; limbah ampas kopi; stabilitas tanah

\begin{abstract}
In the field of land construction is a media base of the core of a building. Soil structure which most abundant clay in its component is the fat Monmorillonite. The method of soil stability in the following research is to use coffee waste in the addition of 5\%,10\%, 15\% and $20 \%$ by conducting Water Content testing and gradation test on the original soil structure used as the research sample, sample soil test taken from the area wilis indah housing town of Kediri which is Montmorillonite. On the results of the study of the structure of the native soil categorized as momoroillonite and after adding coffee pulp on additions varied to a maximum of 20\%, the Liquid Limit value rose to $43 \%$ and the Plastic Limit value increased to $31.64 \%$, so that the plastic index could increase to $11.36 \%$. When the compaction test with the condition of the solid specimen is perfect, the dry volume of the original soil is $6.72 \mathrm{gr} / \mathrm{cm} 3$ and after adding coffee pulp waste by 20\%, the dry volume increases to $10.56 \mathrm{gr} / \mathrm{cm} 3$.
\end{abstract}

Keywords: Soil; coffee waste; soil stability 


\section{PENDAHULUAN}

Dalam ilmu teknik sipil, keamanan sebuah bangunan sangat ditentukan oleh kekuatan strukturnya, baik struktur atas (upper structure) dan struktur bawah (base structure)." [1][2]. Struktur atas meliputi konstruksi kolom, balok dan plat sedangkan struktur bawah meliputi konstruksi pondasi [3] "fungsi dari tanah itu sendiri adalah sebagai media pijakan inti dari sebuah bangunan" [4] dan "pemikul beban dari kolom yang kemudian menyalurkannya ke lapisan tanah keras" [5]. Dengan demikian diharapkan struktur tanah harus kompeten didalam setiap fungsinya. "Lempung ekspansif memiliki potensi kembang susut tinggi apabila terjadi perubahan kadar air", [6]. Menurut E. Bowless dijelaskan bahwa "Lempung bersifat plastis pada kadar air sedang, dalam keadaan kering lempung sangat keras dan tidak mudah dikelupas hanya dengan jari" [4], [7], untuk itu upaya guna stabilitas tanah diperlukan untuk mencapai struktur tanah lebih konsisten [8] [9][10] [11], "Stabilisasi tanah dapat dilakukan dengan cara mekanik yaitu dengan pemadatan menggunakan energi mekanik untuk menghasilkan pemampatan partikel, atau secara kimiawi yaitu dengan mencampur tanah asli dengan bahan tambah tertentu", [6]. Dalam paper berikut ini upaya penelitian yang dilakukan adalah dengan menstabilisasi jenis tanah montmorillonite menggunakan kombinasi limbah ampas kopi dengan variasi $5 \%, 10 \%, 15 \%$ dan $20 \%$ [12] [13] [14] [15][16] [17]. Ampas Kopi setelah proses penyeduhan merupakan limbah yang sulit penguraiannya dan berkategori limbah domestik, "limbah padat domestik yang penguraiannya lumayan sulit, sifatnya padat namun lolos air", [18]. sehingga dapat digunakan sebagai media material stabilitas tanah berjenis monmorillonite dalam penelitian paper yang berjudul Penelitian Stabilitas Struktur Tanah Lempung Bersifat Monmorillonite Menggunakan Limbah Ampas Kopi dengan menggunakan pengujian klasifikasi tanah, batas konsistensi tanah dan pemadatan tanah.

\section{METODE PENELITIAN}

\section{A. Tanah Lempung}

Faktor tingkat dehidrasi struktur tanah lempung sangat berimbas pada sifat mekanik tanah lempung, sedangkan "Kondisi secara umum kadar air pada tanah berubah - ubah dari keadaan jenuh", [19].Struktur tanah yang akan digunakan sebagai media percobaan adalah struktur tanah lempung yang nilai stabilitasnya rendah dan bersifat Monmorillonit.

\section{B. Air}

Air merupakan material yang penting dan banyak digunakan[20]. "Zat kimia ini merupakan sebuah zat pelarut yang penting, memiliki kemampuan untuk melarutkan zat kimia lainya", [21] [7]. Air akan dipergunakan sebagai media pelarut dalam pengujian berikut ini, serta didapat dari saluran air bersih laboratorium teknik sipil Universitas Kadiri.

\section{Limbah Ampas Kopi}

Bahan pendukung yang digunakan sebagai stabilisator tanah dalam penelitian berikut adalah limbah ampas kopi dari sisa penyeduhan minuman kopi yang diambil dari wilayah kediri. Kombinasi Ampas kopi yang akan digunakan dalam stabilitas tanah bervariasi pada jumlah 5\%,10\%, 15\% dan $20 \%$ dari berat total benda uji.

\section{Uji Klasifikasi Tanah}

Uji klasifikasi tanah dalam pengujian berikut ini adalah dengan melakukan uji gradasi butiran struktur tanah asli yang digunakan untuk, "mengetahui jenis sifat tanah asli sebagai media pengujian, [22], adapun langkah yang dilakukan pada pengujian klasifikasi tanah adalah sebagai berikut:[1] Keringkan sampel Tanah pada suhu $200^{\circ} \mathrm{C}$ selama 12 jam hingga kering udara. [2]. Ambil sampel tanah secara random sebanyak 1000 gr. [3] Ayak Tanah dengan ukuran $256 \mathrm{~mm}-$ $0,0625 \mathrm{~mm} \&<0,0625$ gunakan hydrometer. [4]. Letakkan dimesin penggoyang secara bertahap selama 5 menit urutkan dari yang terbesar. [5]. Hitung berat tertahan pada setiap ayakan.

\section{Uji Konsistensi Tanah}

Pengujian konsistensi tanah dilakukan guna, "menentukan kadar air suatu tanah pada keadaan batas cair dan tingkat plastis maksimal", [22]. Pada pengujian ini terdapat 2 pokok pengujian, yaitu uji Liquid limit dan Plastic limit dengan metode pengujian sebagai berikut:[1] Liquid limit, Letakkan 200 gram benda uji kering di atas mangkuk kaca, tambahkan air suling, lalu aduk sampai merata atau homogen. Aturlah tinggi jatuh cawan $5 \mathrm{~mm}$ dengan memutar sekrup yang tercatat dibelakang alat liquit limit (cassagrande). Bagi Tanah menjadi 4 bagian dan masukkan kedalam cawan monel cassagrande per bagian serta ratakan hingga sejajar dengan dasar alat liquit limit. Tekan grooving tool pada benda uji sepanjang diameternya dan grooving tool harus berkedudukan horizontal tegak lurus pada permukaan cawan cassagrande, dan ujung groovinging tersebut harus tidak lebih dari $1,5 \mathrm{~cm}$ tebalnya. Putar handlenya 2 kali hingga kedua belahan benda uji bersatu sepanjang $13 \mathrm{~mm}$. Catat perhitungan sebagai number of blows (jumlah 
ketukan). Jaga ke 4 pengujian untuk mendekati 25 ketukan, bila jumlah ketukan $<25$ maka benda uji kurang air atau jika <25 ketukan maka benda uji terlalu banyak air. Ambil sebagian benda uji pada bagian yang menyatu, masukkan kedalam container untuk dikeringkan (oven) dan hitung kadar airnya.[2]

\section{Plastic Limit}

a. Gunakan tanah dengan lolos ayakan no. 40 sebanyak \pm 20 gram dan jumlah variasi formula mix tanah dengan limbah ampas kopi, letakkan diatas mangkok porselen dan aduk sampai merata kadar airnya.

b. Buatlah bola kelereng berdiameter $1 \mathrm{~cm}$.

c. Giling diatas pelat kaca. Penggilingan dengan telapak tangan dengan kecepatan $80-90$ gilingan permenit sampai membentuk batang lidi diameter $3 \mathrm{~mm}$.

d. Sampel yang tepat bila pada diameter $3 \mathrm{~mm}$ telah keadan retak-retak rambut.

e. Ambil hingga 4 sampel pengujian tentukan kadar airnya.

\section{Uji Kepadatan Tanah (Proctor)}

Maksud dari uji proctor adalah, "menaikkan kerapatan tanah dengan memperkecil jarak antar partikel sehingga terjadi reduksi volume udara dan tidak terjadi perubahan volume air yang cukup berarti", [23]. Adapun langkahnya sebagai berikut :

a) Hitung berat dan volume mold proctor dengan jangka sorong $\&$ tentukan nilainya.

b) Masukkan sedikit - demi sedikit benda uji kedalam mold proctor hinga menjadi 3 layer dengan setiap layer dilakukan penumbukan sebanyak $25 \mathrm{x}$ tumbukan.

c) Lakukan perataan permukaan benda uji dan Hitung kembali berat mold proctor ketika terisi benda uji.

d) Keluarkan benda uji dari mold proctor dan tentukan kadar airnya dengan oven.

\section{HASIL DAN PEMBAHASAN}

Hasil pengujian gradasi tanah dapat disajikan dalam tabel berikut ini :
Tabel.1 Analisis gradasi butir struktur tanah asli

\begin{tabular}{|c|c|c|c|c|}
\hline \multirow{2}{*}{\multicolumn{2}{|c|}{ JENIS PARTIKEL }} & \multirow{2}{*}{$\begin{array}{l}\text { DIAMETER } \\
(\mathbf{m m})\end{array}$} & \multicolumn{2}{|c|}{ JUMLAH } \\
\hline & & & (gr) & $(\%)$ \\
\hline \multirow[t]{2}{*}{$\begin{array}{l}\text { KERIKIL } \\
\text { (GRAVEL) }\end{array}$} & $\begin{array}{l}\text { Builders } \\
\text { Cobbles } \\
\text { Pebbless } \\
\text { Granules }\end{array}$ & $\begin{array}{c}>256 \\
64-256 \\
4-64 \\
2-4\end{array}$ & 0 & 0 \\
\hline & $\begin{array}{l}\text { Very coarse } \\
\text { sand }\end{array}$ & $1-2$ & 3 & 0,3 \\
\hline \multirow{6}{*}{$\begin{array}{l}\text { PASIR } \\
\text { (SAND) }\end{array}$} & Coarse sand & $0,5-1$ & 29 & 2,9 \\
\hline & $\begin{array}{l}\text { Medium } \\
\text { sand }\end{array}$ & $0,25-0,5$ & 40 & 4 \\
\hline & Fine Sand & $0,125-0,25$ & 51 & 5,1 \\
\hline & $\begin{array}{l}\text { Very fine } \\
\text { Sand }\end{array}$ & $0,0625-0,125$ & 74 & 7,4 \\
\hline & $\begin{array}{l}\text { LANAU } \\
\text { (SILT) }\end{array}$ & $0,002-0,0624$ & 546 & 54,6 \\
\hline & $\begin{array}{l}\text { LEMPUNG } \\
\text { (CLAY) }\end{array}$ & $\begin{array}{c}<0,002 \\
\text { (MICRO) }\end{array}$ & 257 & 25,7 \\
\hline
\end{tabular}

Sumber : Hasil Analisis Uji Gradasi Butir di Laboratorium Teknik Sipil Universitas Kadiri

\section{Uji Konsistensi Tanah}

Hasil pengujian ini dapat disajikan dalam tabel dan grafik berikut ini :

Tabel 2. Pengujian batas konsistensi tanah

\begin{tabular}{cccc}
\hline $\begin{array}{c}\text { KADAR } \\
\text { AMPAS } \\
\text { KOPI (\%) }\end{array}$ & $\begin{array}{c}\text { Nilai Luquid } \\
\text { Limit (\%) }\end{array}$ & $\begin{array}{c}\text { Nilai Plastic } \\
\text { Limit (\%) }\end{array}$ & $\begin{array}{c}\text { Index } \\
\text { Plastic } \\
(\%)\end{array}$ \\
\hline 0 & 46 & 19,37 & 26,63 \\
5 & 52 & 22,75 & 29,25 \\
10 & 56 & 24,49 & 31,51 \\
15 & 60 & 25,56 & 34,44 \\
20 & 62 & 30,25 & 31,75 \\
\hline
\end{tabular}

Sumber : Hasil Analisis Uji Batas Konsistensi Keseluruhan Benda Uji Mix Tanah dan Limbah ampas kopi di Laboratorium Teknik Sipil Universitas Kadiri 


\section{BATAS KONSISTENSI MIX TANAH DAN AMPAS KOPI}

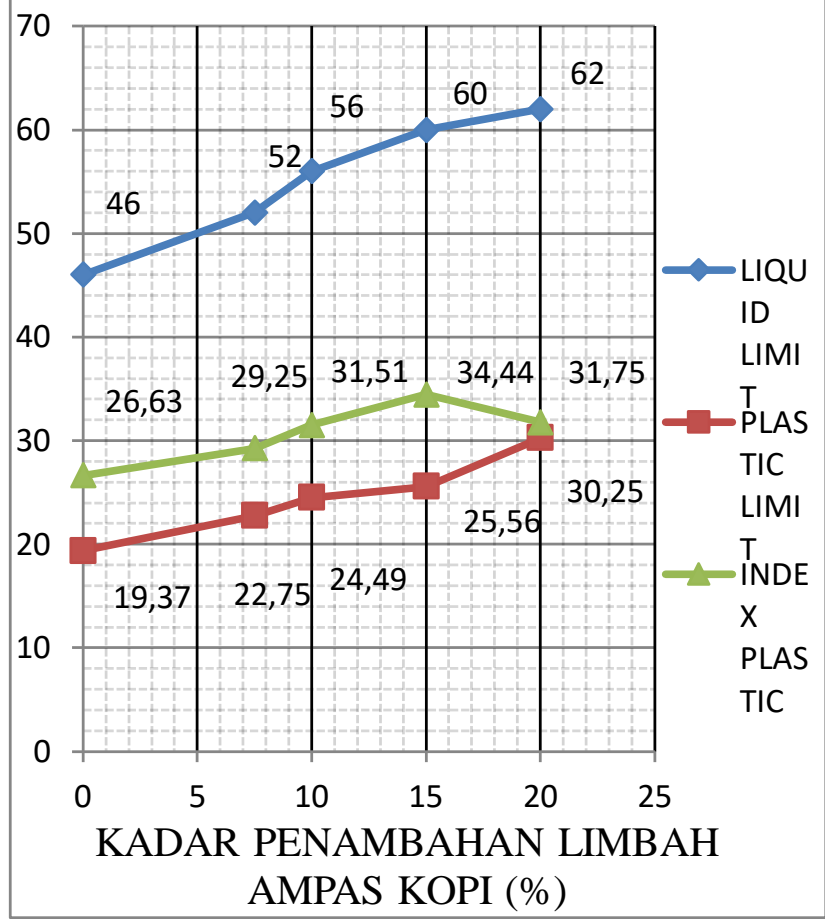

Gambar 1. Grafik Nilai Batas Konsistensi

Dari penelitian dan perhitungan uji konsistensi, Pada indeks plastisitas dengan penambahan 0\% limbah ampas kopi memiliki persentase sejumlah $26,63 \%$ dan persentase fraksi gradasi tanah $<0,002$ $\mathrm{mm}$ sebesar $25,7 \%$, maka sampel tanah yang memiliki nilai aktivitas $36,63: 25,7=1,42$ disimpulkan masuk ketegori jenis mineral lempung Montmorillonite dan pada perbaikan tanah dengan kombinasi limbah ampas kopi sebesar 15\% menunjukkan nilai index plastic struktur tanah konsisten optimal sebesar $34,44 \%$.

\section{Uji Pemadatan Tanah}

Hasil pengujian pemadatan tanah (proctor) disajikan dalam tabel dan gambar grafik berikut ini :

Tabel 3. Nilai uji proctor struktur tanah asli (Montmorillonite).

\begin{tabular}{|c|c|c|c|c|}
\hline BENDA UJI & 1 & 2 & 3 & struktur \\
\hline Berat mold proctor & 4502 & 4502 & 4502 & mensmjukk \\
\hline $\begin{array}{l}\text { Weight water (ww) + } \\
\text { mold }\end{array}$ & 6242 & 6286 & 6493 & kadar $_{6459}$ air 1 \\
\hline Berat benda uji & 1740 & 1784 & 1991 & 1957 \\
\hline Weight solid & 1641 & 1651 & 1810 & 1747 \\
\hline Weight water & 99 & 133 & 181 & 210 \\
\hline Water content & 6,03 & 8,06 & 10,00 & 12,02 \\
\hline Volume mold (v) & 188,28 & 188,28 & 188,28 & 188,28 \\
\hline $\begin{array}{l}\text { Weight volume (ysat) } \\
=\mathrm{w} / \mathrm{V}\end{array}$ & 9,24 & 9,48 & 10,57 & 10,39 \\
\hline $\begin{array}{l}\text { Weight volume solid } \\
(\mathrm{yd})=\mathrm{ws} / \mathrm{v}\end{array}$ & 8,72 & 8,77 & 9,61 & 9,28 \\
\hline
\end{tabular}

Pengujian proctor pada benda uji struktur tanah asli menunjukkan nilai optimum yd sebesar 9,61 pada kadar air 10,57\%.

Tabel 4. Uji proctor kombinasi tanah dengan 5\% limbah ampas kopi.

\begin{tabular}{|c|c|c|c|c|}
\hline BENDA UJI & 1 & 2 & 3 & 4 \\
\hline Berat mold proctor & 4502 & 4502 & 4502 & 4502 \\
\hline $\begin{array}{l}\text { Weight water }(w w)+ \\
\text { mold }\end{array}$ & 6319 & 6472 & 6665 & 6621 \\
\hline Berat benda uji (w) & 1817 & 1970 & 2163 & 2119 \\
\hline Weight solid (ws) & 1712 & 1823 & 1965 & 1891 \\
\hline $\begin{array}{l}\text { Weight water }(\mathrm{ww})=\mathrm{w}- \\
\text { ws }\end{array}$ & 105 & 147 & 198 & 228 \\
\hline $\begin{array}{l}\text { Water content }(\mathrm{wc}) \\
=\mathrm{ww} / \mathrm{ws} * 100(\%)\end{array}$ & 6,13 & 8,06 & 10,08 & 12,06 \\
\hline Volume mold $(\mathrm{v})=\pi \cdot \mathrm{r}^{2} . \mathrm{t}$ & 188,28 & 188,28 & 188,28 & 188,28 \\
\hline $\begin{array}{l}\text { Weight volume (ysat) = } \\
\mathrm{w} / \mathrm{v}\end{array}$ & 9,65 & 10,46 & 11,49 & 11,25 \\
\hline $\begin{array}{l}\text { Weight volume solid } \\
(\mathrm{\gamma d})=\mathrm{ws} / \mathrm{v}\end{array}$ & 9,09 & 9,68 & 10,44 & 10,04 \\
\hline
\end{tabular}

Pengujian proctor pada benda uji kombinasi struktur tanah dengan 5\% ampas kopi menunjukkan nilai optimum yd sebesar 10,44 pada kadar air sejumlah $10,08 \%$.

Tabel 5. Uji proctor kombinasi tanah dengan 10\% limbah ampas kopi.

\begin{tabular}{lcccc}
\hline BENDA UJI & $\mathbf{1}$ & $\mathbf{2}$ & $\mathbf{3}$ & $\mathbf{4}$ \\
\cline { 3 - 5 } Berat mold proctor & 4502 & 4502 & 4502 & 4502 \\
\hline $\begin{array}{l}\text { Weight water (ww) + } \\
\text { mold }\end{array}$ & 6342 & 6534 & 6775 & 6801 \\
\hline Berat benda uji (w) & 1840 & 2032 & 2273 & 2299 \\
\hline Weight solid (ws) & 1752 & 1881 & 2066 & 1999 \\
\hline $\begin{array}{l}\text { Weight water (ww) = w- } \\
\text { ws }\end{array}$ & 88 & 151 & 207 & 300 \\
\hline $\begin{array}{l}\text { Water content (wc) } \\
=\text { ww/ws*100 (\%) }\end{array}$ & 5,02 & 8,03 & 10,02 & 15,01 \\
\hline Volume mold (v) $=\pi . r^{2} . t$ & 188,28 & 188,28 & 188,28 & 188,28 \\
\hline $\begin{array}{l}\text { Weight volume (ysat) }= \\
\text { w/v }\end{array}$ & 9,77 & 10,79 & 12,07 & 12,21 \\
\hline $\begin{array}{l}\text { Weight volume solid } \\
(\mathrm{yd})=\text { ws/v }\end{array}$ & 9,31 & 9,99 & 10,97 & 10,62 \\
\hline
\end{tabular}

Sumber : Hasil Konversi Uji Proctor

Pengujian proctor pada benda uji kombinasi tanah dengan $10 \%$ ampas kopi an nilai optimum yd sebesar 10,97 pada $0,02 \%$. 
Tabel 6. Uji proctor kombinasi tanah dengan $15 \%$ limbah ampas kopi.

\begin{tabular}{|c|c|c|c|c|}
\hline BENDA UJI & 1 & 2 & 3 & 4 \\
\hline $\begin{array}{l}\text { Berat mold } \\
\text { proctor }\end{array}$ & 4502 & 4502 & 4502 & 4502 \\
\hline $\begin{array}{l}\text { Weight water } \\
\text { (ww) + mold }\end{array}$ & 6432 & 6675 & 6895 & 6922 \\
\hline $\begin{array}{l}\text { Berat benda uji } \\
\text { (w) }\end{array}$ & 1930 & 2173 & 2393 & 2420 \\
\hline Weight solid (ws) & 1838 & 2012 & 2175 & 2104 \\
\hline $\begin{array}{l}\text { Weight water } \\
(w w)=w-w s\end{array}$ & 92 & 161 & 218 & 316 \\
\hline $\begin{array}{l}\text { Water content } \\
(\mathrm{wc})=\mathrm{ww} / \mathrm{ws}^{*} 100 \\
(\%)\end{array}$ & 5,01 & 8,00 & 10,02 & 15,02 \\
\hline $\begin{array}{l}\text { Volume mold (v) } \\
=\pi \cdot \mathrm{r}^{2} \cdot \mathrm{t}\end{array}$ & 188,28 & 188,28 & 188,28 & 188,28 \\
\hline $\begin{array}{l}\text { Weight volume } \\
\text { (ysat) }=\mathrm{w} / \mathrm{v}\end{array}$ & 10,25 & 11,54 & 12,71 & 12,85 \\
\hline $\begin{array}{l}\text { Weight volume } \\
\text { solid }(\mathrm{yd})=\mathrm{ws} / \mathrm{v}\end{array}$ & 9,76 & 10,69 & 11,55 & 11,17 \\
\hline
\end{tabular}

\section{Sumber : Hasil Konversi Uji Proctor}

Pengujian proctor pada benda uji kombinasi struktur tanah dengan $15 \%$ ampas kopi menunjukkan nilai optimum yd sebesar 11,55 pada kadar air $10,02 \%$.

Tabel 7. Uji proctor kombinasi tanah dengan $20 \%$ limbah ampas kopi.

\begin{tabular}{|c|c|c|c|c|}
\hline BENDA UJI & 1 & 2 & 3 & 4 \\
\hline Berat mold proctor & 4502 & 4502 & 4502 & 4502 \\
\hline $\begin{array}{l}\text { Weight water (ww) } \\
+ \text { mold }\end{array}$ & 6501 & 6710 & 6940 & 6950 \\
\hline Berat benda uji (w) & 1999 & 2208 & 2438 & 2448 \\
\hline Weight solid (ws) & 1904 & 2044 & 2216 & 2129 \\
\hline $\begin{array}{l}\text { Weight water (ww) } \\
=\mathrm{w}-\mathrm{ws}\end{array}$ & 95 & 164 & 222 & 319 \\
\hline $\begin{array}{l}\text { Water content }(\mathrm{wc}) \\
=\mathrm{ww} / \mathrm{ws} * 100(\%)\end{array}$ & 4,99 & 8,02 & 10,02 & 14,98 \\
\hline $\begin{array}{l}\text { Volume mold }(\mathrm{v})= \\
\pi . \mathrm{r}^{2} . \mathrm{t}\end{array}$ & 188,28 & 188,28 & 188,28 & 188,28 \\
\hline $\begin{array}{l}\text { Weight volume } \\
\text { (ysat) }=\mathrm{w} / \mathrm{v}\end{array}$ & 10,62 & 11,73 & 12,95 & 13,00 \\
\hline $\begin{array}{l}\text { Weight volume solid } \\
(\mathrm{yd})=\mathrm{ws} / \mathrm{v}\end{array}$ & 10,11 & 10,86 & 11,77 & 11,31 \\
\hline
\end{tabular}

Sumber : Hasil Konversi Uji Proctor

Pengujian proctor pada benda uji kombinasi struktur tanah dengan 20\% ampas kopi menunjukkan nilai optimum yd sebesar 11,77 pada kadar air sejumlah $10,02 \%$.
Tabel 8. Hasil konversi uji proctor dengan Berat jenis

\begin{tabular}{cccc}
\hline $\begin{array}{c}\text { AMPAS } \\
\text { KOPI }\end{array}$ & $\begin{array}{c}\text { NILAI } \\
\text { PROCTOR } \\
(\mathbf{y d})\end{array}$ & $\begin{array}{c}\text { BERAT JENIS } \\
(\mathbf{B j})\end{array}$ & $\begin{array}{c}\text { HASIL (C } \\
\mathbf{0} \mathbf{B j}) \\
\mathbf{g r / c m 3}\end{array}$ \\
\hline 0 & 9,61 & 2,66 & 3,61 \\
5 & 10,44 & 2,55 & 4,09 \\
10 & 10,97 & 2,51 & 4,37 \\
15 & 11,55 & 2,44 & 4,73 \\
20 & 11,77 & 2,37 & 4,97 \\
\hline
\end{tabular}

Sumber : Hasil Konversi Uji Proctor

Keseluruhan benda uji mix tanah dan limbah ampas kopi di laboratorium teknik sipil Universitas Kadiri.

Nilai yang ditunjukkan pada perhitungan tersebut adalah ketika benda uji struktur tanah asli memiliki berat volume kering ( $\mathrm{\gamma d}$ ) sebesar 3,61, pada kombinasi tanah asli dengan 5\% ampas kopi menunjukkan nilai berat volume kering ( $\mathrm{\gamma d}$ ) sebesar $4,03 \mathrm{gr} / \mathrm{cm} 3,10 \%$ sebesar $3,36 \mathrm{gr} / \mathrm{cm} 3,15 \%$ sebesar $4,73 \mathrm{gr} / \mathrm{cm} 3$ dan pada penambahan sejumlah $20 \%$ adalah sebesar $4,97 \mathrm{gr} / \mathrm{cm} 3$.

\section{KESIMPULAN}

Pada perhitungan Index Plastic terbesar adalah pada benda uji tanah asli dengan penambahan Limbah ampas kopi sejumlah $15 \%$ yang memiliki tingkat selisih liquid limit dan plastic limit paling tinggi, yakni $34,44 \%$. Pada pengujian pemadatan tanah benda uji dengan penambahan limbah ampas kopi sebesar 20\% dari berat benda uji adalah hasil optimum uji pemadatan setelah dilakukan konversi keselarasan berat jenis. Yakni memiliki nilai berat volume kering ( $\mathrm{\gamma d}$ ) sebesar 4,97 gr/cm3. Nilai tersebut merupakan nilai kepadatan diatas rata rata pengujian jika dibanding dengan benda uji yang lainnya.

Dengan acuan pada batasan masalah yang tidak memperhitungkan nilai ekonomis dalam pengaplikasian, sebagai praktisi maupun aplikator dalam pengerjaan suatu kegiatan diharapkan selalu memperhitungkan segala resiko 


\section{REFERENSI}

H. Wahyudiono. 2018. "Perencanaan Pondasi Bore Pile Pada Proyek Jembatan Ngujang Ii Kab.Tulungagung" UKaRsT, vol. 2, no. 1.

A. I. Candra, A. Yusuf, and A. R. F. 2018. "Studi Analisis Daya Dukung Pondasi Tiang Pada Pembangunan Gedung Lp3M Universitas Kadiri" J. CIVILA, vol. 3, no. 2, p. 166, 2018.

A. I. Candra. 2017. “Analisis Daya Dukung Pondasi Strauss Pile Pada Pembangunan Gedung Mini Hospital Universitas Kadiri" Ukarst, vol. 1, no. 1, pp. 63-70.

A. I. Candra. 2018. "Studi Kasus Stabilitas Struktur Tanah Lempung Pada Jalan Totok Kerot Kediri Menggunakan Limbah Kertas" UKaRsT, vol. 2, no. 2, p. 11.

T. Pancang, "Perencanaan pondasi tiang pancang" pp. 1-9.

A. Susanto. 2009. "Pengaruh Stabilisasi Tanah Lempung Dengan Aspal Emulsi Klasifikasi Tanah" vol. 3, no. KoNTekS 3, pp. 6-7.

Das Braja M. 1988. "Mekanika Tanah (PrinsipPrinsip Rekayasa Geoteknis)" Jilid 1, vol. 1. Erlangga.

Pranoto. 2013. "Stabilisasi Tanah Lempung Dengan Penambahan Limbah Sawit Terhadap Nilai California Bearing Ratio" Jurnal and T. Sipil vol. 9, no. 2, 2013.

D. Leon. 2011. "Universitas Diponegoro Stabilitas Tebing Pada Proyek Jalan Tol Semarang Cliff Stability In Toll Road Project Semarang" pp. 6-8.

G. M. E. Sompie, O. B. A. Sompie, and S. Rondonuwu. 2018. "Analisis Stabilitas Tanah dengan Model Material Mohr Coulomb dan Soft Soil" J. Sipil Statik, vol. 6, no. 10, pp. 783-792.

S. Miskah, L. Suhirman, and H. R. Ramadhona. 2014. "Pembuatan Biobriket Dari Campuran Arang Kulit Kacang Tanah Dan Arang Ampas Tebu Dengan Aditif Kmno 4" J. Tek. Kim., vol. 20, no. 3, pp. 12-21.

D. P. Ekananta. 2018. Digital Digital Repository Repository Universitas Universitas Jember, vol. 1 , no. 3 .
D. Ilmu, D. A. N. 2017. Pertanian, "Formulasi Dan Efektivitas Sabun Cair Penyanitasi Dengan Ekstrak Ampas Kopi Dalam Menghambat Pertumbuhan," Teknologi, and F. T.

H. P. Rekso Ajiono. 2019. "Kombinasi Abu Daun Fakultas Teknik Universitas Kadiri" vol. 3, no. 2, pp. 103-112.

R. Suhariyanto, E. Purwanti, D. Setyawan, F. Hardian, and A. Fauzi. 2020. "Kemampuan absorben arang aktif ampas kopi dalam mengurangi kadar limbah industri laundry" pp. 234-251, 2020.

R. Yuliet. 2010. "Identifikasi Tanah Lempung Kota Padang Berdasarkan Uji Klasifikasi Teknik Dan Uji Batas-Batas Konsistensi Atterberg" J. Rekayasa Sipil, vol. 6, no. 2, p. 19.

W. Darmawan, A. Rachmansyah, and Y. Zaika. 2018. "Perubahan Stabilitas Tanah Akibat Penambahan Kapur, Semen, dan Fly Ash pada Tanah Lunak Proyek Tol GempolPasuruan" J. Tek. Sipil UB, no. c.

S. P. R. Wardani, M. Muhrozi, A. R. A. Setiaji, and D. R. Riwu. 2018. "Stabilisasi Tanah Ekspansive dengan Menggunakan Tanah Putih untuk Tanah Dasar di Daerah Godong Kabupaten Grobogan Jawa Tengah" Media Komun. Tek. Sipil, vol. 24, no. 1, p. 1.

Y. C. S. Poernomo. 2008. Pengukuran kadar air tanah menggunakan gypsum block, vol. 2, no. 1.

A. I. Candra, H. Wahyudiono, S. Anam, and D. Aprillia. 2020. 'Kuat Tekan Beton Fc' 21 , 7 Mpa Menggunakan Water Reducing And High Range Admixtures" J. CIVILA, vol. 5, no. 1.

E. Siswanto. 2019. "Penambahan Fly Ash Dan Serat Serabut Kelapa Sebagai Bahan Pembuatan Beton" UKaRsT, vol. 3, no. 1, p. 48.

A. Khanif. 2008. "Stabilitas Tanah Lempung Menggunakan Limbah Padat Pabrik Kertas Terhadap Kuat Geser Tanah" no. 1, p. 1.

M. R. Abdurrozak. 2017. "Stabilisasi Tanah Lempung Dengan Bahan Tambah Abu Sekam" vol. XXII, no. 2, pp. 416-424. 